\title{
Anke Fiedler
}

University of Brussels, Belgium

\section{Michael Meyen}

University of Munich, Germany

\begin{abstract}
Using the example of the former German Democratic Republic (GDR), this study deals with the public sphere in Eastern European countries before 1989. It supports the thesis that even the 'guided' and controlled daily press enabled the readers (even in a limited way) to observe the process of communication and to make up their own minds. The article is based on two main sources: files from the Federal archives in Berlin and a series of 100 biographical interviews, held between 2000 and 2002, in which former GDR residents have been asked about their everyday media usage during the 1980s. This article discusses the concept of public communication and propaganda and shows how the politically staged public sphere operated from the point of view of the rulers and professional readers as well as regular subscribers.
\end{abstract}

\section{Keywords}

German Democratic Republic, media steering, newspapers, political public relations, public sphere, socialism

\section{Corresponding author:}

Anke Fiedler, University of Brussels, Avenue Franklin Roosevelt 50, 1050 Brussels, Belgium.

Email: afiedler@ulb.ac.be 


\section{Introduction}

Using the example of the German Democratic Republic (GDR), this study aims to analyse the practice of newspaper reading in socialist states through the lens of the concept of 'public sphere' (Öffentlichkeit). At first glance, this approach seems somewhat controversial. Previous research continues to uphold the thesis that there was no such thing like a public sphere in socialist countries (in the Western normative sense of the word) and that mass media predominately tried to mould and shape public opinion in the direction favoured by the leading communist party (Bytwerk, 1999; Holzweißig, 2002). These studies usually accord an overwhelming power to the Marxist-Leninist ideology, describing the media as 'collective propagandist, agitator and organiser' - the guiding principles for communist media policies (Boyer, 2005: 122; Boyle, 1992).

On the occasion of the German National Prize Awards in Weimar on 16 June 2009, for instance, the theologian Richard Schröder said that 'there had been no free, collective public sphere' in the GDR and that 'censorship of public opinion' was still having consequences up to the present time. 'The absence of a free press' serves to explain why East Germans are still not able to reach consensus on how the GDR regime was to be assessed and judged (Schröder, 2009). The historian Gunter Holzweißig has established that 'the publicly stated political dogma of Lenin's thought' remained sacrosanct right to the end of the domination of the Socialist Unity Party SED (Sozialistische Einheitspartei). The logical consequence was 'boredom and a content that lacked in informative substance' (Holzweißig, 2002: VII). Research has shown that 'detailed instructions and guidance' were transmitted over the phone and by mail (Kapitza, 1997: 59) and that the media were 'uniform' both in form and in content (Tiemeyer, 1986: 25) due to a hackneyed conformism, a mapping of taboos and out-of-date information. These findings make it plain why the bulk of research about the public sphere in the GDR focuses on the literature and culture, on opposition groups and on the church and leaves out 'the official public sphere under party control' (Silberman, 1997: 7).

Along with Jörg Requate (1999), this study supports the view that the 'dichotomy between the propaganda role of the State's media infrastructure on the one hand and the partially free space in the fields of literature and arts on the other' actually limits the scope of research and makes 'it impossible to see the structure of public communication' (p. 27). Although a quick look into the thin, slowly decaying newspapers with pictures of the General-Secretary of the GDR, political session reports and mottoes is enough to convince of the 'totalitarian destruction of the public sphere in societies ruled by State socialism' (Habermas, 1990: 47), two questions remain unanswered, namely: why did so many people subscribe to these papers and why did the SED not release its practice of influence and control, since it knew that the majority of consumers considered the GDR media to be untrustworthy and that, as a consequence, it would not be feasible to create the socialist individual and to attain to the objective of educative dictatorship (Classen, 2007: 558).

During the last decade of the GDR, the circulation of newspapers was on average one and a half copy per household. Three out of four households had a subscription to a local party newspaper and Neues Deutschland (mouthpiece of the SED) and Junge Welt (mouthpiece of the communist youth Freie Deutsche Jugend (FDJ)) were clearly above 
the 1 million mark. How was it that the press, the so-called sharpest weapon of the Party could enter in most homes? The rulers knew that readers turned down the 'pink-red eyeglasses', political phraseology, irrelevant statistics and long boring articles about agricultural achievements; they knew it at the latest when major revolts broke out in the mid 1960s. Earlier research had reached similar conclusions (Meyen, 2001: 74-82, 229-238). Why then did things not change?

The thesis that postulates the 'insignificance' or the 'irrelevance' of the dailies in the GDR is contradicted by the high circulation of the papers and the effort that was put right to the end into providing guidance and exercising control (Fiedler, 2014). Of course, printed media were cheap in the GDR and circulation rates of newspapers could be controlled through newspaper licences issued by the governmental press office (Presseamt) at the Council of Ministers. But in reality, the SED could never meet the population's demand for newspapers at any time. The limitations placed upon the possibility to subscribe more papers demonstrate that subscriptions represented more than a mere perfunctory function, as these limitations were imposed even on the Party papers. If the GDR had been able to acquire more papers, the number of subscriptions would have risen even higher.

This study supports the thesis that even the 'guided' and controlled daily press created a public sphere in the GDR and enabled the readers (even in a limited way) to observe the process of communication and to make up their own minds. This public sphere did not provide an intermediary system for debate that would have allowed for bilateral exchange between politics and society and given free access to everyone (Gerhards and Neidhardt, 1990: 42-46). Yet, even in the GDR there was a 'domain that was not secret' and that related to State affairs which is the original definition of the concept of public sphere. As public communication took place via daily papers 'within the horizon of all citizens' (a relevant specificity of the public sphere in the State system) and as readers were largely aware of both the objectives and the mechanisms of political steering of the media that was going on, public opinion could emerge in the GDR and represent more or less general positions with regard to specific issues. These opinions could not really touch upon all issues (examples of taboos on communication such as the construction of the wall or the Prague Spring), but these opinions did not necessarily have to be in agreement with the objectives of the official communication policy. By comparison, the television and radio offer from the German Federal Republic towards the GDR has influenced the process of public opinion making in less concrete ways (because Western German Television could only dedicate a comparatively limited amount of air-time to GDR issues and did not cover the whole GDR territory), but they have largely contributed to raising the awareness of the audience to the phenomenon of media steering that was going on in the GDR.

To support this thesis, section 'Public sphere and media control in the GDR' will, first, discuss the concept of public communication and propaganda and, second, serve to demonstrate that the 'positive connotation' of the concept of public sphere has restrained the research into the performance of the politically staged public discourse in the socialist States of Eastern Europe (Gerhards and Neidhardt, 1990: 31, 51). If we had not concentrated on the 'secondary public sphere' and on the publication 'Encounter' or if we had not denied the existence of a public sphere, the mobilization process of the public sphere 
that took place in the GDR in the summer of 1989 would not have taken us so much by surprise (Gerhards and Neidhardt, 1990: 77). Section 'Sources' summarizes the methods and sources used for this report. Section 'Politically staged public sphere in the GDR' will show, with the support of a chain of arguments, how politically staged public sphere operated, from the point of view of makers as well as of the professional reader (politicians and business leaders at home and abroad, who understood the GDR press as it was meant, namely, as a public relation operation) and finally through the eyes of the regular subscriber.

\section{Public sphere and media control in the GDR}

Research into the public sphere in the GDR usually refers either to Jürgen Habermas or to the Arena Model of Jürgen Gerhards and Friedhelm Neidhardt. Both models assume that public sphere is an unclear concept (Gerhards and Neidhardt, 1990: 32) with a plethora of concomitant meanings (Habermas, 1989). Both then accept that in the course of functional differentiation, a system of public sphere emerged that serves as an intermediary between society (or the world of life) and politics (Boggs, 2000). Consequently, Habermas, as well as Gerhards and Neidhardt, concentrates on the 'political public sphere' (Habermas, 1990: 38; Dahlberg, 2004), and they do thereby take on board 'a normative element' that has belonged to the concept ever since the Enlightenment: 'Public sphere always implies that the affairs of the State should be open, i.e.: accessible to the general public. They must relate to the reasoning of citizens and their opinions' (Gerhards and Neidhardt, 1990: 32). It follows that in both concepts public sphere is a 'political term' that relates to the democratic system.

While public sphere in the liberal theory of democracy, to which the Arena Model belongs, ranks rather low and does not represent high priorities, Habermas and his followers make it into an emphatic term and a kind of regulatory idea, that makes high claims from communication (such as political actors close to the citizens, who legitimize their claims on strong grounds, renounce rhetorical tricks and care for a consensus), an idea that can therefore hardly materialize in reality (Gerhards and Neidhardt, 1990: 33), least of all in the GDR. Even the 'type-representative public sphere' that Habermas elaborated for the feudal society (Habermas, 1990: 58-67) does not really prove usable in the analysis of structures of communication in the socialist states because public sphere and private sphere there, as in all industrialized societies, were kept separate and because the SED leaders, in striking resemblance to princes and despite all pretence to the contrary ('The Party is always right', 'Dictatorship of the proletariat'), could not simply represent power, they had to legitimize it through public communication.

Gerhards and Neidhardt have coined the expression 'politically staged public sphere', and they wrote that there had actually been 'an encounter public sphere' in the GDR. In the Arena Model, they distinguish three levels of public sphere (Scheme 1): alongside the mass media communication, without which there can be no public sphere in complex societies, they defined events and meetings related to public sphere as well as 'small public spheres' (such as dialogues on the bus, at the workplace or at the pub), all of which only played a minor role in the given model. Encounters are practically unlimited as to their participants and issues and they represent the capacity to record and to control the 
message circulated by the mass media, yet at the same time these 'small public spheres' remain very fragile and unstructured. In totalitarian systems, this may be an advantage (in that it is averse to political control), but on the other side the regime's secret service are quite aware of the relevance of these episodes of interaction to the point that even such Encounters need to rely on tactics to protect themselves (Gerhards and Neidhardt, 1990: 50-52). Scheme 1 shows the distinctions of the Arena Model for the GDR, as found in research papers, although what David Bathrick (1995) described as 'anti-public sphere' should probably be classified in the events related to public sphere category. Here, (author removed) have in mind publications which were produced mainly in the 1980s by opposition groups or by artists in the GDR, often under the auspices of the Church, but only reached out to so limited circles of readers that they can hardly be described as mass media.

Scheme I. Arena Model of the public sphere (Gerhards and Neidhardt, 1990).

Mass communication

- GDR media (guided and controlled media, 'politically staged public sphere')

- Western media ('primarily broadcasting media but also other publication outlets', Silberman, 1997)

- 'Unofficial or counter public' (Bathrick, 1995)

Public events and meetings

Encounter ('small public spheres')

The fact that research has mainly focused on the 'counter-public sphere' and that it has in addition overestimated the influence of the Western media (Bathrick, 1995; Silberman, 1997) can be explained in view of the theoretical background and the normative claims that surround the concept of political public sphere:

- Public sphere needs to be open for all groups in society as well as for all issues and opinions that have a collective relevance (role of transparency).

- The actors involved in public sphere have to handle issues and opinions of others in a discursive manner (validation role).

- This is how public opinions can emerge and be perceived as convincing and accepted by the public at large (role of orientation).

As no autonomous media system emerged in the GDR, on the contrary, mass communication remained dependent on the political system, and the politically staged public sphere could not deliver these functions, at least not as is the case in democratic public spheres. Western media and underground publications provided only a limited alternative. First, quite a large number of GDR citizens had no access to the products of the counter-public sphere, neither did they have the possibility to listen to or to watch the radio and television output from the West Germany (some of them because of technical reasons, others because this would have contradicted their convictions), and second, 
reporting was limited in every respect, in its scope, in its topics and in its analysis. Even the interviewees, who demonstrated a clear pro-Western inclination during the biographical interviews, said that they would not have believed the ARD and ZDF main television broadcasters from Western Germany (Meyen and Schwer, 2007).

The GDR media were not autonomous and could not constitute a public 'system of debate', that provides an intermediary between the political system and the citizens, yet all other dimensions of a media system are also represented there: a professional production of media content that competes for the attention of the public (among one another and at least in the field of radio with the broadcast from the West), a public that remains 'fundamentally un-excluded'. The fact that public communication 'within the horizon of all citizens' was happening (Gerhards and Neidhardt, 1990: 45, 47) allowed the leadership of the SED (as will shortly be demonstrated) on the one side to use the media for political public relations (PR), yet on the other side this contributed to the emergence of a public sphere that could, at least in a limited sense, fulfil a role of validation and orientation because the citizens knew that the media were being steered and controlled as the Western media constantly reminded them.

We define PR here along with Klaus Merten (2008) as the 'management of the difference between facts and artefacts'. As the communist ideology always moved along in the background like a film, these 'facts' did not necessarily correspond to objective truths, rather to already reproduced realities (Merten, 2005: 8). Ideology helped to interpret, to classify, and to select what had happened and finally to prepare a fiction of these reproduced realities. Merten described PR specialists as the 'professional builders of fictional realities' who make every effort to represent issues constantly in a positive tone (Merten, 2005, 2008: 51), with the final aim 'to manipulate the perception in the public sphere to their own ends'. This definition is pertinent in the 'media society' (since Merten holds media contents to be fundamentally fictional, the need for PR emerges to make it possible to transform the image of persons, companies, events or ideas), and this definition does at the same time refer to its origin in the first communicative mode, namely, propaganda (Merten, 2008: 48-49, 54).

We need to clarify that this study deals with political PR and not (as in most research on the GDR) with propaganda (Bytwerk, 1999; Holzweißig, 2002). If one follows the theory of totalitarianism, dictatorships cannot be imagined in the 20th century without propaganda. Hannah Arendt (1958) has described the transformation of the factual into a fictional world, that Merten sees as constitutive for all media, as the main characteristic of totalitarian movements, and she has reckoned with the essential role of propaganda first in the mobilization phase. Friedrich and Brzezinski (1965) have focused more on the consequences of media control and postulated that although people do actually pull back from public sphere and mistrust official information because of the constant barrage of slogans, this type of brainwashing eventually leads them to integrate specific stereotypes, images and values in their own thinking.

First, there is only very shaky (empirical) evidence to support this postulate; second, the term propaganda is so negatively loaded that it does pre-empt the result on the actual analysis (one-sidedness, illegitimacy and strong effects); and third, as Classen (2007) convincingly demonstrated, it remains unclear how propaganda can be distinguished from PR, advertising and education: 'Where does propaganda begin and where does it 
end?' (p. 552). The term 'political PR' seems therefore to relate to the staged public sphere rather than to the concept of propaganda.

\section{Sources}

This article is based on two main sources. The first kind of sources and data that served to elaborate the following segments comes from the Federal archives in Berlin. Documents from the section for agitation at the Central Committee of the SED and from the other media relevant sections in the Central Committee of SED covering the period under consideration have all been drawn into the research. These files provide information about the structures that influenced the media as well as about the communication process at play in the background.

The second source is a series of 100 biographical interviews, held between 2000 and 2002, in which former GDR residents have been asked about their everyday media usage during the 1980s. Although radio and TV audience research was conducted in the GDR, findings were not published until 1989 and are of doubtful value. GDR citizens had plenty of reasons not to trust the anonymity of surveys, and Western media were virtually completely excluded from this kind of research. Moreover, without support from the Western powers and without market competition, representative studies were not undertaken until the middle of the 1960s. That is why we decided to collect memories connected to the media usage. Especially when it comes to evaluating the importance of media offerings for daily life, qualitative methods are superior to standardized interviews. Biographical interviews describe typical variants at best, although making no claim to be exhaustive. Researchers should be aware that this form of interview is simply unable to provide information about the distribution of certain patterns of action within the entire population. Furthermore, some of the universe (in this case, citizens of the former GDR) are no longer alive or too old to be able to remember accurately. On the other hand, such interviews require a person's willingness and ability to tell a stranger about his or her life. Both qualities do not prevail to the same degree in the various strata of the population. To allow for generalizations nonetheless, respondents were selected by theoretical sampling. This technique posits that a field of action, such as media consumption, is characterized by a finite number of varieties (Lindlof, 1995: 126-131). The sample of this survey is based on findings of usesand-gratifications research and knowledge of media consumption in industrialized societies. Initially it was assumed that most demographic influences on media usage are trans-cultural and do not differ between West and East Germany (different media use of men and women, of city slickers and villagers, of people with different ages and formal education). The second presumption was that the consumption and evaluation of media offerings are connected with the population's general attitude towards social systems. For the case of the GDR, this means that people who were climbing the career ladder in the party apparatus, elected full-time officials and employees in managerial positions were indicative of those approving the system. On the contrary, people with a religious background, families of artists and doctors, craftsmen, self-employed people, shop owners and those who left the country before the collapse of the regime in 1989 were assumed to disapprove of it. 
The sample was selected by students who have been trained to interview respondents during one semester. Since people have difficulties to remember changes occurring in the course of time, the interviews focused on the second half of the 1980s. First of all, interviewers surveyed biographical data, followed by a reconstruction of a normal day in the respondent's life, sometime in the final period of the GDR. These questions helped to refresh memories (media consumption and everyday life are closely interrelated) and to overcome inhibitions. The interview guide only listed the subjects to be discussed, thus enabling respondents to describe their own view of the issues, to mention episodes and to set priorities. Unlike completely open forms of interviews, the guide ensured a minimum of comparability. It included the following topics: life in former East Germany, access to media programmes, patterns of media consumption and motives, media evaluation (credibility, image), life at present (economic situation, media consumption, current image of the GDR).

\section{Politically staged public sphere in the GDR}

This segment uses the sources on structures of communication in the socialist countries, mentioned above, to support the thesis that the politically staged public sphere has, partially at least, served to accomplish what is expected from the public sphere in democratic societies and (unwillingly) contributed to the collapse of the GDR regime. The format of the present article only allows us to include limited archive evidence and results of questionnaires to support the successive stages of the argument.

Thesis 1. The steering of the media in the GDR was a PR operation. The management of the difference between facts and artefacts served the purpose to support the interests of the rulers, in their interaction with the West and in the competition to win the minds of their own citizens. It follows that the specific instructions can only be understood with due regard for the internal and international political situation. Whenever the publishing of specific information could endanger current interests, the persons in charge were held accountable.

This process can be demonstrated in detail in the transmissions of the agitation section, the governmental press office and the Secretaries of the Office of Agitation. Heinz Geggel, who was director of the Agitation Section as of 1973, instructed the chief editors on 29 May 1980 to consider 'our collective state and economical interests' as the supreme guideline for reporting, and he requested from them not 'to put anything into the public domain that would run counter to that interest'. This meant for instance 'to support all progressive forces' and to present the 'ongoing events' in Iran as 'a true people's revolution'. Günter Schabowski, who was the editor-in-chief of the SED mouthpiece Neues Deutschland, agreed with that view in 1981. The class struggle meant 'to engage with the weapons and the fighting techniques that grant optimum political results according the concrete circumstances'. After attending a seminar, Schabowski wrote to the director of the state-controlled press office, Kurt Blecha: 'What serves the interests of socialism, of the GDR', this is the question one had to start from and that would lead to report about 'Japan, France and Italy, or this or that Scandinavian country' in a way that is distinct 
from the reporting about other 'imperialistic countries'. 'The economic ties to Japan would be an advantage for Socialism', and anyway one should 'exploit the different and even contradictory interests to the advantage of Socialism and against Imperialism'.

Guiding principles were set down in concrete instructions on an everyday basis and guided the controllers. On 19 March 1970, the Secretary for Agitation Werner Lamberz instructed the chief editors to cover the meeting between Willy Brandt (chancellor of the Federal Republic of Germany (FRG)) and Willi Stoph (Prime Minister of the GDR) in Erfurt, at which thousands of GDR citizens had warmly welcomed the West-German Chancellor. Lamberz told them to dedicate 'extra care and attention to the expression of support of the GDR population for our politics and Government as well as to the claims put to the Government of the FRG'. When the mouthpiece of the East-German Trade Union (Freier Deutscher Gewerkschaftsbund (FDGB)) the Tribüne reported about unemployment in Austria in 1983, the chairman of the FDGB Harry Tisch was consulted. The article dealt with facts, but their publicizing was 'not politically correct' in the immediate follow-up to the visit by the Federal President of Austria. ${ }^{1}$

Thesis 2. The people in charge have consistently implied that 'the other side' (in particular the FRG) was on the lookout for weaknesses of the GDR in all its publications, and they made every effort to suppress the reporting of any internal details that their adversary might have used for their own interest.

This thesis is supported by the article in the FDGB newspaper Tribüne about Austria, which falls in the category of diplomacy. In 1977, Lamberz turned down a press statement from the Ministry of Interior about a session with leading military officers because 'such a piece of information would become an item in the Western media for days on'. The information, which came from the Minister of Interior Friedrich Dickel in person, might have given the impression that public order was 'particularly threatened' and could not be maintained without the support of the Soviet militia (which Dickel had mentioned expressly).

The argumentation could get even trickier when it had to do with the essential, foreign currency-related matter of external trade. In 1983, the East-German central news agency Allgemeiner Deutscher Nachrichtendienst (ADN) announced an export contract for bullet chargers with France. Günter Mittag, in charge of economy within the Central Committee, asked Erich Honecker, the then General-Secretary of the Central Committee, to give up 'the publication of such news in the future'. 'The reactionary spheres' would try at any cost to prevent exports from the GDR and would take advantage of such news to influence the political conditions so that the GDR could be dismissed as a supplier (for reasons of competition). Since it was not possible to keep silent about relations to nonsocialist countries, Mittag suggested that it was possible to publish information about 'participation in fairs and exhibitions' or 'trips of delegations and personalities' but in 'no case any concrete buyers or other facts'. ${ }^{2}$

Thesis 3. Since the political PR operation had to support the interests of the rulers, it was directly attached to the centre of power. The agitation secretaries and the leaders 
of the SED Walter Ulbricht (1950-1971) and Erich Honecker (1971-1989) decided personally even the details of media steering.

Gunter Holzweißig (2002) spoke about 'Generals-Editors in Chief' and wondered at the fact that General-Secretary Erich Honecker took the time to draft 'announcements, commentaries and articles' for the leading media by himself. First, this does not seem so surprising for someone who conceives the steering and control of the media as a political PR tool, and second, the files show that this was not the end of it. Even trivialities such as the 10-line announcement of the ADN about the bullet-charger contract in 1983 were drafted by Honecker himself. It was a matter of handling isolated sentences and specific formulations, as for instance in the case of an $\mathrm{ADN}$ announcement about a negotiation in the US Ministry for Agriculture on 11 November 1976 (just about 20 lines) in which General-Secretary Honecker supported a proposal of Agitation Secretary Lamberz to rewrite the beginning and the first two descriptive sentences to make sure that the GDR 'would not appear to be in a position of pleading'.

The Agitation Secretaries kept Erich Honecker permanently informed of the foreign reactions to the news published in the GDR. The top of the SED hierarchy exploited the GDR media environment to the fullest extent, in particular for its foreign relations. When the party speaker of the West-German Social-Democratic Party (Sozialdemokratische Partei Deutschlands (SPD)) Hans-Jochen Vogel gave an interview to the news agency ADN in 1986, in which he wanted to announce his position on the facilitation of travel procedures in the GDR, Honecker decided on the advice of Herrmann, to publish it in the upcoming issue of the foreign policy monthly Horizont (on an inside page). Vogel had let it to the GDR to decide where to publish the interview. ${ }^{3}$

Thesis 4. The most important stakeholders of the political public relation operation (politicians, ambassadors, businessmen and artists, who had to deal with the GDR) used to read the East-German press as it was conceived (namely, as an official statement of the SED), and they tried to draw conclusions about the position and the objectives of the GDR leadership.

Herbert Okun, US Ambassador to the GDR from 1980 to 1983, told Joachim Herrmann, Agitation Secretary in the 1980s, in a private interview on 22 January 1981, that he started his day 'with the study of the SED mouthpiece Neues Deutschland' because this was 'the first competent information about the politics of the GDR'.

Similar statements can be found mainly in the files that cover the activities of the Permanent Representative of the FRG in the GDR. In 1982, Klaus Bölling (Permanent Representative from 1981 to 1982), for instance, asked Lothar Kolditz, the President of the national council of the National Front of the GDR, if it had anything to do with the events in Poland that the GDR newspapers currently insisted so heavily on order, cleanliness and security. During an informal discussion on 1 February 1985, Hans-Otto Bräutigam (Permanent Representative from 1982 to 1989) praised the measured reaction of the GDR media to the 'recent political statements in the FRG about Silesia' and went on to ask, "what had been the objective of an article in the SED-controlled Neues 
Deutschland about respect for State citizenship'. The West-German Social-Democratic Party would probably 'keep a low profile' after the publication of that article. ${ }^{4}$

Thesis 5. The objectives and the mechanisms of media steering were known not only to the Western politicians but as well to the GDR citizens. The management of difference between facts and artefacts may have caused large numbers of readers to leave out the first pages of the daily newspapers; on the other hand, politically interested citizens had the possibility to draw conclusions. Although the politically staged public sphere was neither open to all topics nor for all actors, it did in a way at least provide a certain measure of transparency and orientation.

The judgement on the politics of information fell with a vengeance in the above-stated biographical interviews. Nobody said that they ever trusted the East, not even the people who still defend the SED media policy in retrospect. Most of the interviewees spoke of the 'anger of mature citizens' and complained about 'political narrow-mindedness' and 'stupid and bad' propaganda. A nursery school teacher, who was member of the SED Party, said the media had been the mouthpiece of the Central Committee. 'Tendentious? Tendentious does not even begin to describe the situation'. And the school teacher who ascribed hidden interests to the class enemy said she had always had the impression that 'she was constantly being lied to in the GDR'. These findings are not linked to the specificities of the time when the interviews were conducted (10years after the fall of the Berlin Wall, focus on the 1980s). There are no reasons to believe that the local media at any time in the GDR were worthy to be believed. Whenever people were interviewed, they complained about the 'pink-red eyeglasses', about the endless statistics and slogans.

The available sources, not unlike the biographical interviews, cannot provide information about statistical categories. Yet, unless the collected data should be fully misguided, one can conclude that large swathes of the population (in particular women, who were fully occupied in their daily lives and people who were by and large happy with their own lives in the GDR) used the media from East and West primarily for entertainment and avoided political reporting - either from the GDR media or from the television and radio programmes from the FRG. In addition to that, there is one type of consumer (in the Church environment) who deliberately avoided the SED news as a matter of principle. Among the elites in the GDR society (leaders in the economy, the SED Party and the administration) in the circles of declared opponents to the regime (to which for instance artists and priests and ministers or intellectuals could belong) and among people who felt rejected by the GDR (because they had been denied social advancement, because they felt they were not paid enough or because they had hit the wall with the administration), among all these categories, the GDR newspapers were read with as much attention as they were read by the US Ambassador Okun or the Permanent Representatives Bölling and Bräutigam. A church minister, born in 1942, said in a biographical interview that he read Neues Deutschland because that was where the SED opinion stood. 'We read that to find out how specific things were interpreted by officialdom. How was the report put together, what was being reported and what was left out. How was it to be interpreted?'

Since the GDR citizens knew that the papers were not independent, the political media steering of the SED provided them (unintentionally) with information that they needed for their own guidance. 'Nothing negative was supposed to happen in Socialism', 
said a nursery school teacher, born in 1944. 'I think they would even have tried to ignore an earthquake'. 'No one ever listened to success stories, such as the results of elections for instance, something so ridiculous' and then more of the 'absurd reports about milkmaid $\mathrm{X}$ and worker Y', all of that resulted in the fact that no one believed anything the GDR media carried, not even the 'critical reports' about life in the FRG.

Thesis 6 . The 'politically staged public sphere' did not only provide information (albeit indirectly) about the objectives of the rulers and the views of their negotiation partners, it did also fulfil an orientation function, because it informed about the currently valid reading of the ideology, about what one could do and say without rubbing the system up the wrong way.

Noelle-Neumann (1984) defines public opinion as opinions people must display 'at a certain time and at a certain place' in order not to become isolated, or opinions that they can display, 'without getting expelled from their present bond'. In the biographical interviews, we find plenty of evidence to the thesis that even a steered mass media provides this type of orientation, in particular to people who move about in domains that are controlled by the Party or that it considers important (educational facilities, public administrations, armed forces).

The daily papers supplied not only the topics about which the next meeting on the following day would debate but as well the official point of view and the corresponding formulations, the way one had to express things, without risking to stand out isolated or even to put one's position or career to risk. Suffice it to quote two examples: a school director, born in 1932 said, 'he did not study each copy in details, but did make press clippings of what was necessary for his work and kept them. It was important. These were facts and reports that I could use for the teaching'. A female school teacher from the region of Rostock remembered the World Peace Day, the day when the school year started and she had to tell the children about World War II (WWII). The newspapers did provide statistics, for instance about the number of people who died in the war, and gave instructions on how to pay tribute to the victims (author removed, 2007).

Thesis 7 . The knowledge that the daily newspapers had a high significance for the SED and that there were close ties between the newsrooms and the decision makers had the consequence that the GDR citizens turned to the press and even to the Secretary for Agitation in the Central Committee of the SED, not because they believed that their cases would be published but because they knew that their letters would get to the relevant administration (in case of specific problems) or to the centre of power. The daily newspapers in the GDR represented a channel for discussion that provided an intermediary between the politics and the population. Owing to the fact that this system for discussion was not public, this structure of communication may have hampered processes of social change as well as the regime's adaptation to the changing global environment in the 1980s.

Readers' letters were analysed thoroughly in newsrooms. The Central Commission for Revision of the SED ordered 'a processing without delay and worthy of the Party' in an examination in 1980. 'All petitions and readers' letters had to be registered, to receive 
answers in a timely manner or to be transmitted to third parties for treatment (such as administrations). In case this 'third party' did not write back to the inquirer, it was possible to consider the publication of 'an official blame in the newspaper'. On the occasion of press fairs, which every newspaper organized once a year as a kind of popular festival, the papers promoted actively the concept of readers' letters with a view to" stimulate creative cooperation with the participants'. In the quality report for the Neues Deutschland, there was praise for the fact that readers received 'personal distinct answers that were, if needed, elaborated in consultation with relevant experts'. In the 1970 s and in the 1980s, the mouthpiece of the SED received on average 5000 or 6000 readers' letters per year, many of them expressed their approval for the course of the Party or for the line of the newspaper. Petitions mostly related to issues of accommodation and supplies.

The newsrooms of the Party's bulletins summarized the issues contained in the readers' letters and the views expressed in regular reports. These were analysed by the section for agitation and classified in dossiers. On 10 February 1978, one could read in such a file that the construction workers in East-German city Cottbus debated

whether they had not gotten carried away in their plans to build apartments and should need a corrective plan, that the majority of citizens would welcome the introduction of a few VW Golf vehicles, yet other people complained that the cars were only meant for those who had money and wondered whether it would not have been wiser to buy something 'more essential in view of the shortage of foreign currency'. 5

It was worthwhile to write letters to the newspapers and to the Agitation section because it represented a direct link to the SED leadership, and it enabled citizens to communicate about issues that requested attention and to point to the direction in which this should ideally happen (in democratic societies, the intermediary discussion system operates in the public sphere). When a personal problem could not be solved this way or in a meeting of readers, then it stood very little chance of being solved anywhere.

This policy of the individual case, while avoiding the public sphere, had two advantages for the rulers: on the one hand, critiques were, at least temporarily, satisfied, and on the other hand, GDR citizens could only find out about the concerns of their neighbours in 'small public spheres' and had more difficulty to get informed about public opinion at large. Politics and citizenship had opportunities to exchange views, even about central ideological questions; on the one hand, it happened between the levels of mass communication and the level of public events (both of which could have been admitted by opponents from the West) and in the public sphere of encounters on the other hand.

\section{Conclusion}

Of course, political PR are a reality in democratic societies. Yet the fictions spread by parties, by governments and at public events do not get into the public domain 'unfiltered'; much rather, they feed into a relatively autonomous system of mass communication. The first duty of this system (which is stipulated in law) is to operate as an intermediary discussion system between citizens and politics. Second, this system has 
developed professional criteria for the selection and the processing of information (objectivity, transparency of sources, diversity), and third, it caters and responds to the needs of the public. The observation of the GDR demonstrates that this intermediary discussion system is essential in the public sphere because it boosts the credibility of political news. Although many citizens distrust journalists and the media and although the operations of politics and journalism are closely intertwined, the present-day situation can in no way compare to the GDR setup. In the GDR, the top ranking hierarchy of the SED had direct control on the newsrooms, and numerous announcements were not only written by the General-Secretary himself but even strategically published on the page of his choice. The SED leadership saw the press as an instrument in the class struggle, and it positioned a fiction in the part of the public sphere that it could control directly; this fiction or artefact was meant to serve their current interests, and it did take into account that the Western media also played a role in the GDR public communication sphere.

The citizens of the GDR knew that there was no 'free' public sphere in their country (Schröder, 2009), and they have therefore generally distrusted news and the media, even the media offer from the FRG. Anyone with an interest in politics and a readiness to invest time in newspaper reading (which was by far not everyone's case, just like in any other society) could draw conclusions from the fictions published in the politically staged public sphere on the problems and objectives that the rulers and their interlocutors in world's politics had discussed. This was of course enhanced by following the news reporting from the FRG.

When the SED top leadership kept specific topics out of the domain of public communication or when it reacted with a notable delay, the possibility remained to discuss problems and to make oneself an opinion that diverged from the published views. This happened in encounters, under the auspices of the churches and via the products of the 'counter-public sphere' despite their limited outreach. It must be said that the wave of protest that caused the end of the SED rule was also boosted by the fact that reality and media fictions were ever growing further apart. It can nevertheless be safely assumed that the GDR citizens had plenty of opportunities to read signs of the agony of the system in the politically staged public sphere. Since validation could only happen within encounters, the process of build-up of political will has taken longer than it does in societies with an autonomous system of public sphere.

This article can be read as an address for a theory of the public sphere that can explain the communication structures in the socialist societies in Eastern Europe. On the basis of the Arena Model developed by Gerhards and Neidhardt, there are two sub-levels to distinguish in the level of mass communication: the politically staged public sphere, as it was used by the SED for political PR, and the media from the West which correspond to counter-public sphere. The dominance of the mass media has allowed for the emergence of an unofficial communication structure that has provided (within limitations) opportunities to connect society (or the real world) with politics. The collected readers' letters and the files of the section for agitation demonstrate that this discourse can be gauged with the norms of Habermas, largely because the involved citizens had no means to know how the rulers would react and needed not only courage but as well rhetorical capacities in support of their argument. 


\section{Funding}

This research received no specific grant from any funding agency in the public, commercial or not-for-profit sectors.

\section{Notes}

1. Quotes from original documents of the Central Committee of the Sozialistische Einheitspartei (SED): Bundesarchiv (German Federal Archive), SAPMO-BArch, DC 9/1119; DY 30/IV 2/2.033/33, p. 9; DY 30/IV 2/2.037/16, p. 71.

2. SAPMO-BArch, DY 30, DY 30/IV 2/3.033/35, pp. 169-174, here 169; DY 30/IV 2/2.037/7, pp. 49-51, here 49.

3. SAPMO-BArch, DY 30/IV 2/2.037/4, p. 40; DY 30/IV 2/2.037/8, pp. 118-125, here 118.

4. SAPMO-BArch, DY 30/IV 2/2.037/100, pp. 29-32, here 30-31; DY 30/IV 2/2.037/06, pp. 93-94, here 94; DY 30/IV 2/2.037/17, pp. 4-8, here 5-6.

5. SAPMO-BArch, DY 30/IV 2/2.037/23, pp. 13-22, here 20; DY 30/IV 2/2.037/24, pp. 83-97; DY 30/IV 2/2.037/14, pp. 1-5.

\section{References}

Arendt H (1958) The Origins of Totalitarianism. New York: Meridian Books.

Bathrick D (1995) The Power of Speech: The Politics of Culture in the GDR. Lincoln, NE: University of Nebraska Press.

Boggs C (2000) The End of Politics: Corporate Power and the Decline of the Public Sphere. New York: Guildford Press.

Boyer D (2005) Spirit and System: Media, Intellectuals, and the Dialectic in Modern German Culture. Chicago, IL: University of Chicago Press.

Boyle M (1992) Capturing Journalism: Press and Politics in East Germany, 1945-1991. San Diego, CA: University of California.

Bytwerk R (1999) The failure of the propaganda of the German Democratic Republic. Quarterly Journal of Speech 85: 400-416.

Classen C (2007) Thoughts on the significance of mass-media communications in the Third Reich and the GDR. Totalitarian Movements and Political Regimes 8: 547-562.

Dahlberg L (2004) The Habermasian Public Sphere: a specification of the idealized conditions of democratic communication. Studies in Social and Political Thought 10: 2-18.

Fiedler A (2014) Medienlenkung in der DDR. Cologne: Böhlau.

Friedrich CJ and Brzezinski ZK (1965) Totalitarian Dictatorship and Autocracy. Cambridge, MA: Harvard University Press.

Gerhards J and Neidhardt F (1990) Strukturen und Funktionen moderner Öffentlichkeit: Fragestellungen und Ansätze. Berlin: Wissenschaftszentrum.

Habermas J (1989) The Structural Transformation of the Public Sphere: An Inquiry into a Category of Bourgeois Society. Cambridge, MA: The MIT Press.

Habermas J (1990) Strukturwandel der Öffentlichkeit. Frankfurt am Main: Suhrkamp.

Holzweißig G (2002) Die schärfste Waffe der Partei: Eine Mediengeschichte der DDR. Köln: Böhlau.

Kapitza A (1997) Transformation der ostdeutschen Presse: 'Berliner Zeitung', 'Junge Welt' und 'Sonntag/Freitag' im Prozess der deutschen Vereinigung. Opladen: Westdeutscher Verlag.

Lindlof T (1995) Qualitative Communication Research Methods. Thousand Oaks, CA: Sage.

Merten K (2005) Progress in public relations by improving controlling and measurement. Paper presented to the 12th international public relations research symposium public relations metrics: evaluation and measurement, Lake Bled, 1-3 July 2005. 
Merten K (2008) Zur Definition von Public Relations. Medien \& Kommunikationswissenschaft 56(1): 42-59.

Meyen M (2001) Hauptsache Unterhaltung. Mediennutzung und Medienbewertung in Deutschland in den 50er Jahren. Münster: Lit.

Meyen M and Schwer K (2007) Credibility of media offerings in centrally controlled media systems. A qualitative study based on the example of East Germany. Media, Culture \& Society, 29(2): 285-304.

Noelle-Neumann E (1984) The Spiral of Silence: A Theory of Public Opinion - Our Social Skin. Chicago, IL: University of Chicago Press.

Requate J (1999) Öffentlichkeit und Medien als Gegenstände historischer Analyse. Geschichte und Gesellschaft 25(1): 5-32.

Schröder R (2009) Selbst die Zahl der Selbstmorde war in der DDR ein Staatsgeheimnis. Süddeutsche Zeitung, 23 June, p. 6.

Silberman M (1997) Problematizing the 'Socialist Public Sphere': concepts and consequences. In: Silberman M (ed.) What Remains? East German Culture and the Postwar Public. Washington, DC: American Institute for Contemporary German Studies, pp. 1-37.

Tiemeyer F (1986) Eine Spur ausführlicher: Ein Vergleich zwischen der SED-Presse und den Zeitungen der 'Blockparteien'. Medium 16(2): 25-26. 